\title{
Evolutionary history of plant diversity on the Kunlun Mountains
}

\author{
Weibo $\mathrm{Du}^{1}$, Peng Jia ${ }^{1}$, and Guozhen $\mathrm{Du}^{2}$ \\ ${ }^{1}$ State Key Laboratory of Grassland and Agro-Ecosystems, School of Life Sciences, \\ Lanzhou University \\ ${ }^{2}$ State Key Laboratory of Grassland and Agro-Ecosystems
}

March 26, 2021

\begin{abstract}
Large-scale patterns of biodiversity and the underlying mechanisms that regulate these patterns are central topics in biogeography and macroecology. The Qinghai-Tibetan Plateau (QTP) is a natural laboratory for studying these issues. However, most previous studies have focused on the entire QTP, and the independent physical geographical subunits in the region are not well understood. We studied the current plant diversity on the Kunlun Mountains, an independent physical geographical subunit located in northwest China, on the northern edge of the QTP. We integrated measures of species distribution, geological history, and phylogeography, and analyzed the taxonomic richness, origin time, and community phylogenetic structure of the plants present in the area. The distribution patterns of 1,911 seed plants highlighted that species were located mainly in the eastern regions of the Kunlun Mountains. Chinese endemic species of seed plants accounted for $29.8 \%$ of the total species on the Kunlun Mountains. The biodiversity patterns and mean divergence times (MDT) indicated that the eastern region of the Kunlun Mountains was the center for biodiversity conservation, particularly in the southeastern region, which has served as a museum for plant diversity on the Kunlun Mountains. According to the MDT, the origin time of the Kunlun Mountains' flora (KMF) was early Miocene (19.40 Ma), and the KMF is ancient. The biogeographical roles of the Kunlun Mountains were corridor and sink, and the corresponding key processes were species immigration and extinction. The extant biodiversity on the Kunlun Mountains has occurred through species recolonization after climatic fluctuations and glaciations during the Quaternary. The Kunlun Mountains also formed a barrier, representing a boundary among multiple floras, and converted the QTP into a closed physical geographical unit. The nearest taxon index indicated that habitat filtering may have played an important role in biodiversity patterns.
\end{abstract}

\section{Hosted file}

Manuscript-Finally.pdf available at https://authorea.com/users/312339/articles/515425evolutionary-history-of-plant-diversity-on-the-kunlun-mountains 

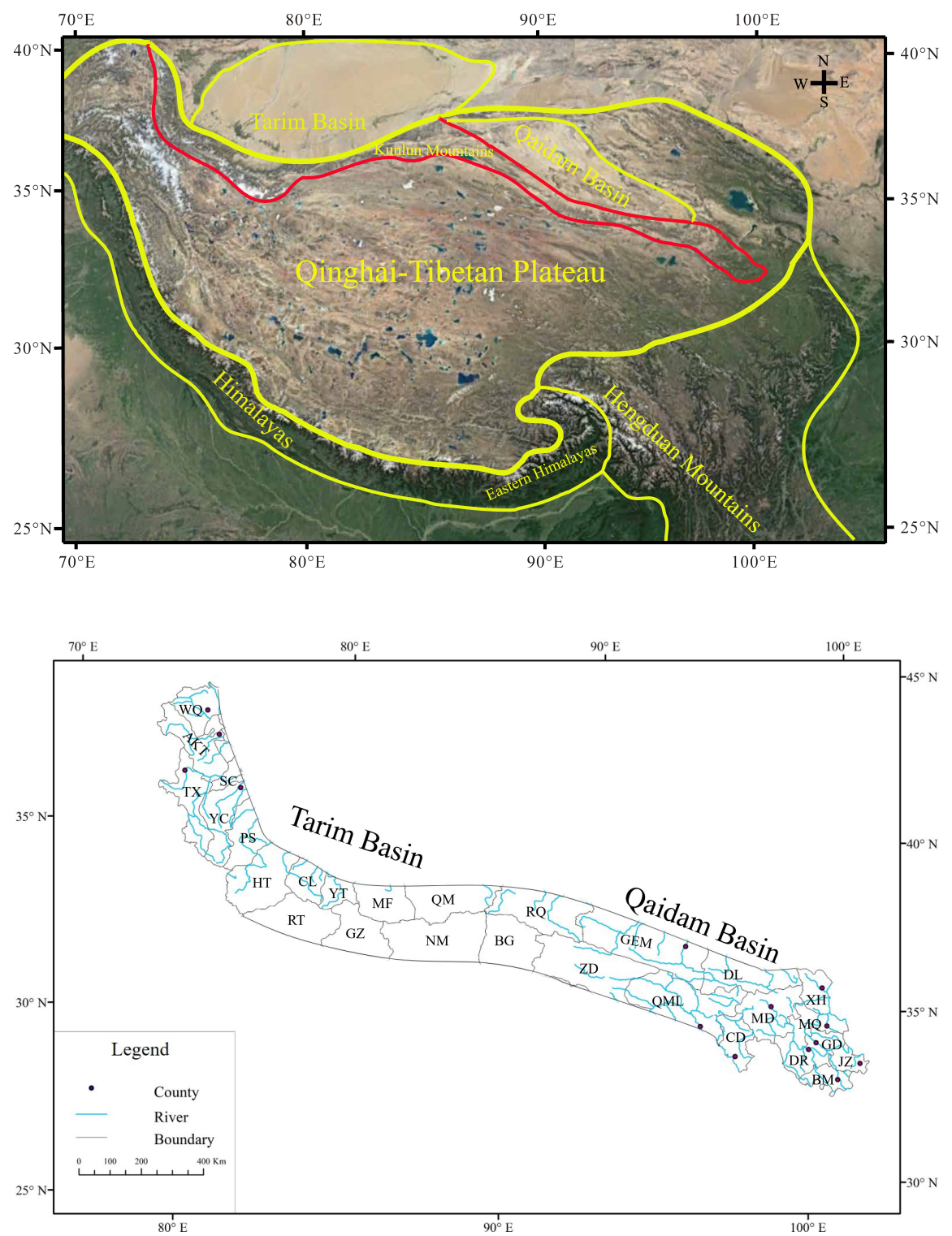

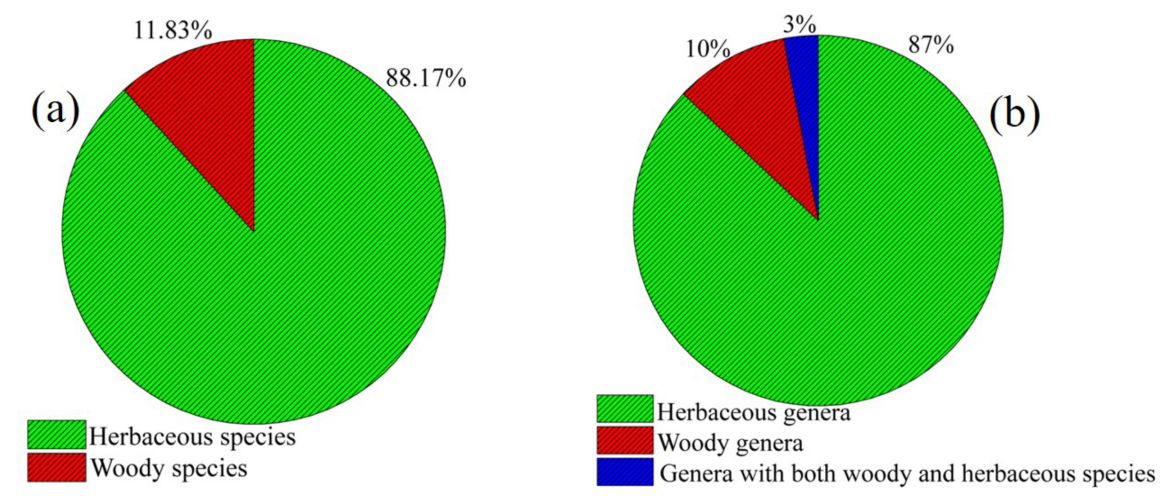

(c)
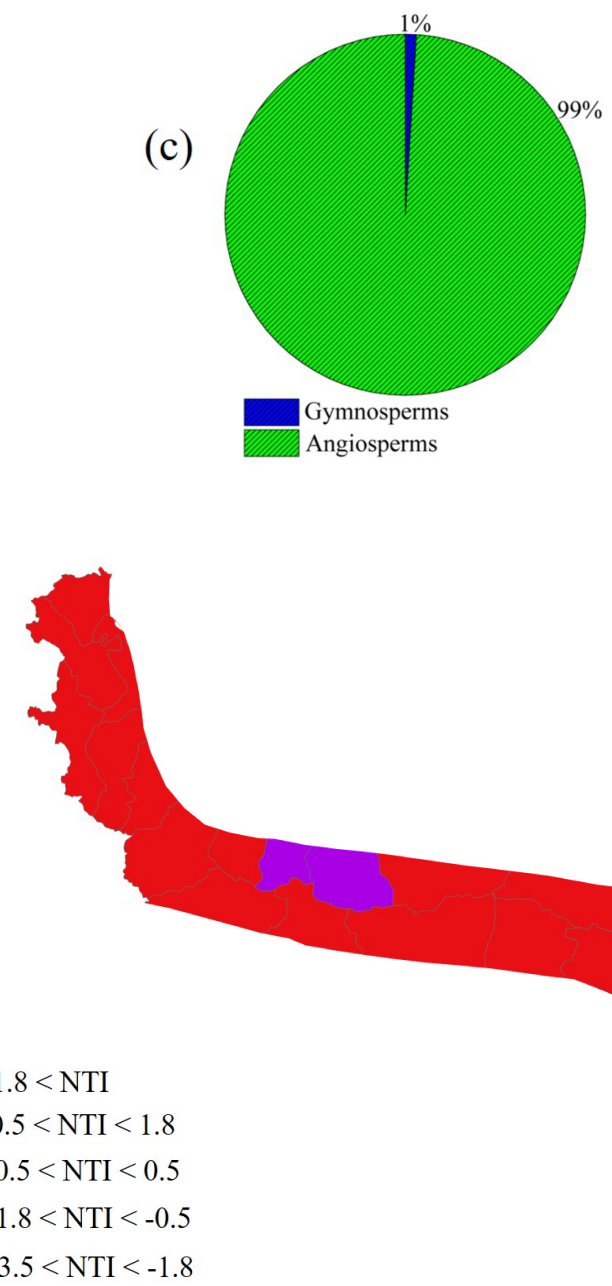